\title{
WestVirginiaUniversity.
}

Department of Economics

Working Paper Series

\section{Replacement Referees and NFL Betting Markets}

Bryan McCannon

Working Paper No. 15-20

This paper can be found at the College of Business and Economics Working Paper Series homepage: 


\title{
Replacement Referees and NFL Betting Markets
}

\author{
Bryan C. McCannon \\ West Virginia University \\ \& Center for Free Enterprise*
}

10 January 2015

\begin{abstract}
Are betting markets efficient? The 2012 labor dispute between the NFL and the referees is used as a quasi-experiment to assess whether the betting markets are able to achieve accurate "prices" in an uncertain environment. More points were scored and underdogs performed relatively better resulting in upsets and closer-than-expected games. Betting markets, though, were unable to anticipate or adjust to this systematic effect even though irregularities in gambling markets were reported before the beginning of the season. Not only were they inefficient, but profitable betting strategies can be identified.
\end{abstract}

JEL Codes: D40, L1

Keywords: betting markets, efficiency, gambling, over-under, replacement referees, spread

\footnotetext{
* Department of Economics, 1601 University Avenue, Morgantown, WV 26506, bryan.c.mccannon@gmail.com. I would like to thank Joe Coate, Craig Depken, Rodney Paul, Jeff Peterson and Mark Wilson for helpful discussions and comments.
} 


\section{INTRODUCTION}

Between the 2011 and 2012 football seasons a labor dispute arose between the NFL and the union representing the referees. The dispute lasted into the preseason and through the first three weeks of the season. After notorious refereeing decisions and a strong negative response from fans and the sports media an agreement was reached and the professional referees returned. In their absence replacement referees were used. This provides a quasi-experiment to assess the impact of refereeing quality on the game.

Prior to the beginning of the regular season many media outlets reported on occurrences in National Football League (NFL) betting markets during the preseason. It was widely reported that there was unusual betting. Specifically, the "over" bets in the over-under frequently won. The over-under is a bet placed on the total points to be scored by both teams in a game. If a gambler takes an over bet, then s/he is predicting that more points will be scored than the stated amount. Additionally, the favored team fared worse in that the anticipated margin of victory was closer than expected, the "spread". Furthermore, it was also reported that more money was expected to be placed on the over bets and speculation arose as to whether the over-under and the spread would be adjusted for the upcoming regular season games. ${ }^{1}$ The betting irregularities were covered in media outlets such as The Wall Street Journal, New York Times, USA Today, ESPN, NPR, and Bloomberg (to name a few). Specifically, the USA Today, reporting that the over bets won substantially more often, speculated, "it will be interesting to see if that continues early in the regular season, to see if the oddsmakers make an adjustment to that.”2

\footnotetext{
${ }^{1}$ See http://espn.go.com/nfl/story/_/id/8402489/nfl-replacement-officials-affecting-vegas-bets and http://www.businessweek.com/news/2012-09-20/nfl-scoring-sets-record-as-vegas-adjusts-to-replacement-referees. ${ }^{2}$ http://usatoday30.usatoday.com/sports/football/nfl/story/2012-08-30/replacements-gambling/57457746/1
} 
This raises the question as to how will both oddsmakers and gamblers respond to this new situation. The replacement referees create uncertainty. Will oddsmakers accurately identify expected point differences and points scored and adjust to them or will there be profitable bets available for consumers? This is especially poignant given that the irregularities were reported and known prior to the beginning of the season giving all market participants the opportunity to adjust. To address the impact of less-skilled referees on betting markets, betting lines along with game outcomes are collected and analyzed from the 2012 NFL season. This information is used to ask whether the replacement referees affecting the scoring and margin of victory as compared to the professional referees. Was there less accurate betting markets?

Straightforward results arise. With regards to the margin of victory it is shown that with the replacement referees the favored team fared poorly. Specifically, a wedge was driven between the spread in the betting market and the actual margin of victory. Underdogs did better, but betting markets did not adjust for the employment of the replacement referees. The margin of victory shrunk and the favored team was both less likely to cover the spread and less likely to win the game. Additionally, profitable strategies exist. With regards to total points scored, there was a positive and statistically significant increase in scoring, but no change in the totals line. Hence, there were inaccuracies in the betting markets. The analysis is replicated for the 2011 season and it is shown that games during the first three weeks of the season do not differ in the margin of victory or total points scored metrics (actual, betting lines, or difference between the two) and that the favored team was no less likely to win or cover the spread. Thus, the results are not driven by any early season effects.

The results presented contribute to the discussion of the efficiency of sports betting markets. Attention has been focused primarily on searching for potential inaccuracies in NFL 
betting markets (Lacey, 1990; Dare and MacDonald, 1996; Gray and Gray, 1997). Golec and Tomarkin (1991) and Dare and Holland (2004) investigate the strategy of betting on the home team when it is not favored. Borghesi (2007a) shows that this effect is enhanced late in the season. Vergin and Sosik (1999) find that bets on underdog home teams in games with national attention are inaccurate. Borghesi (2007b; 2008) identifies the effect of weather on home teams’ success and total scoring. Paul and Weinbach (2002) identify a profitable betting strategy focusing on games that are expected to be high scoring with a wide margin of victory. Vergin (2001) shows that there is an effect of outstanding, positive performance in the previous game on betting, while the potential effect of differences in playing surfaces is discussed (Boulier, Stekler, and Amundson, 2006). Chin (2011) investigates the time of day of the game. Nichols (2014) finds that team travel affects outcomes but is not fully incorporated into betting lines. Finally, Ottaviani and Sørenson (2009) consider betting strategies with asymmetric information. What distinguishes the work presented here is the novelty that the potential irregularities were reported before the betting took place. Rather than investigate historical data for inaccuracies, I investigate whether knowing the distortions are arising, do market forces correct them.

The work also contributes to the debate regarding the behavior of oddsmakers (Woodland and Woodland, 1991). While it has been claimed that they set the lines to balance the number of dollars bet on both sides of the gamble, the existence of systematic inaccuracies and profitable betting strategies suggest alternative objectives (Levitt, 2004; Paul and Weinbach, 2007; Humphreys, 2010). The results presented lend support to these observations.

Section II presents the description of the data used. The econometric analysis is reported in Section III, while Section IV concludes. 


\section{DATA}

The final scores for all NFL regular season games in the 2012 season are collected. From this the variables Margin and Total are created. Margin is the difference between the number of points scored by the team favored to win and the number of points scored by the team not favored to win. Total is simply the total number of points scored.

Additionally, betting market information is collected. Data on the three primary types of bets in football is included. The spread is the anticipated difference in the points scored between the two teams. The over-under is the anticipated total number of points to be scored by both teams. The moneyline allows one to choose who will win the game, but the gain if correct depends on the expected likelihood of victory. The betting information was collected from five separate and popular oddsmakers. They are Bovada, JustBet, SBG Global, Betonline, and 5dimes. Including data from five sources mitigates the possibility of irregular bets at one location affecting the results. Furthermore, data was collected on the day of each game to provide the most accurate betting lines. Hence, Spread is the average spread from the five oddsmakers, while $O U$ is the average over-under from the five.

From these two sources, the difference between the actual outcome of the game and the betting numbers can be determined. OffSpread and OffOU are the difference between the actual point difference and total points scored, respectively, and the betting lines. A positive value for OffSpread indicates that the favored team won by more points than required by the spread (so that betting for the favored team wins - “covers”). A positive value for OffOU indicates that the 
total points scored exceed the over-under amount (so that the over bet wins). Additionally, GapSpread and GapOU are the absolute value of the difference between the actual and betting lines.

A number of control variables are included in the analysis. It is recorded whether the game occurred on a Thursday or Monday night ${ }^{3}$, along with whether the game was played within a domed stadium. ${ }^{4}$ Also, it is recorded whether the home team is favored to win. Whether the home team is in the AFC or NFC, along with whether both teams are in the same conference, is measured as well. Finally, dummy variables are created indicating whether the spread/over-under bets were being accepted at all five offshore sites along with whether moneyline bets are accepted by all five. Table 1 presents the variables measured and the descriptive statistics.

[Insert Table 1 here.]

With regards to the margin of victory the favored team scores slightly more than the betting line would predict. Similarly, a little more is scored by the teams in the contest than expected by the over-under bet. For almost all games spread and over-under bets were available from all five oddsmakers, but it is rather frequent for a site to not take moneyline bets.

\section{ANALYSIS}

First, a comparison between the games with replacement referees can be made to those games with the regular referees. Table 2 summarizes.

\footnotetext{
3 The Wednesday night games during the first week of the season is counted as Thursday $=1$, while the Saturday night game in Week 17 is measured as Monday $=1$.

4 The Roof dummy variable also includes those teams who have stadiums with retractable roofs.
} 
[Insert Table 2 here.]

While the replacement referees were in action the favored team did not win by as big of a margin as expected (a zero value to OffSpread signifies a game where the margin of victory equals the spread). With the regular referees the favored team actually does better than the betting markets expected. With both groups there was more scoring than the over-under amount. Interestingly, favored teams fare significantly worse with the replacement referees. These results are consistent with the media speculation that with the use of replacement referees underdogs fare better. A formal econometric analysis is needed, though, to verify the significance of this difference.

Table 3 presents the results with OffSpread as the dependent variable. A constant term is included in each specification, but not reported.

[Insert Table 3 here.]

The econometric results support the previous evidence. Replacement referees are associated with a wedge being driven between the expected point difference set by the betting markets and the actual points scored. Underdogs fare better. This signifies a potential inefficiency in the betting market as the odds set do not fully reflect the most accurate assessment of the outcome of the game. Even though it was widely reported before the beginning of the regular season that replacement referees allowed the team not favored to win to do well, 
the betting lines set do not fully incorporate this information. The statistical significance of this result is robust to the specification considered. ${ }^{5}$

Other than the effect of replacement referees, many of the other control variables do not have much of an impact on the accuracy of the betting markets. One exception is games played in domed stadiums. This could be explained by home teams performing relatively better in bad weather (Borghesi, 2007b). Additionally, if moneyline bets were not taken by all sites for a particular game, then favored teams performed well.

The second column includes the variable Premium. Premium is the degree to the "unfairness" of the bets. ${ }^{6}$ Specifically, the moneyline bets provide payoffs from betting on a team to win (rather than cover a spread). From the moneyline bet the expected probability of a "fair" bet can be determined, or rather, it can be calculated at what probability of victory would make the expected payoff to the bet for a team equal to the amount invested. Adding the probability of each team winning together creates the variable Premium (averaged across the five oddsmakers recorded). Since the oddsmakers set the odds to make a profit, Premium must exceed one. ${ }^{7}$ The results in the second and third column indicate that the larger the premium (with more "unfair" bets) the more inaccurate the spread line is.

The third column also includes the spread to allow for nonlinear effects. Larger spreads are more likely to have the favored team cover.

\footnotetext{
5 The statistical significance of the coefficient on Replace remains if, rather than clustered standard errors, heteroskedastic-robust standard errors are calculated.

${ }^{6}$ Premium is basically the vig for moneyline bets.

7 The mean value of Premium is 1.033 with a minimum of 1.025 and a maximum of 1.046 . To calculate Premium consider the following example. Suppose betting on Chicago to wins pays -150, while betting on Green Bay in their game pays +120 . The former means that a bet of $\$ 150$ is needed to earn a $\$ 100$ gain (if correct). Hence, a "fair" bet would set the expected outcome, p(250) + (1-p)(0) equal to 150 . Hence, the fair probability Chicago wins is $0.6(=$ $150 / 250)$. For Green Bay +120 means a $\$ 100$ bet gains $\$ 120$. Hence, the fair-bet probability is $q=0.455(=$ 100/220). Consequently, Premium $=\mathrm{p}+\mathrm{q}=1.055$.
} 
Not surprisingly, the goodness of fit measurements reveal weak specifications. This suggests that, for the most part, the betting markets are efficient.

A similar analysis can be done with the over-under bet. Table 4 presents the results. Again, a constant term is included but not.

[Insert Table 4 here.]

There is little that can predict the gap between the over-under amount and the total points scored. Other than Monday night games exhibiting a systematic reduction in scoring, the variable that does statistically affect the accuracy of the totals line is the presence of replacement referees. The positive coefficient suggests that there is more scoring with the replacement referees than with the permanent officials. Hence, the uncertainty injected into the game by the substitute officials leads to inefficiencies in the gambling on margin of victory as well the total points scored.

The question arises, though, as to whether the wedge is driven by a change in outcomes on the field or by changes in the lines set by the oddsmakers. Table 5 presents the effect of having replacement officials on other measurements of outcomes. Along with a constant term each specification includes all control variables previously reported (Column I of Tables 2 and 3), but are not reported. ${ }^{8}$

[Insert Table 5 here.]

\footnotetext{
${ }^{8}$ The sign and statistical significance of the results persist if the specifications in Columns II and III are used instead.
} 
With regards to the total points scored, there is an increase in scoring with the replacement referees, and a small increase in the over-under line. The former is statistically significant, while the latter effect is indistinguishable from zero. The distance from the overunder is unaffected by the officials. Thus, the wedge is caused by changes in outcomes of games without corresponding corrections in the betting markets.

With regards to the margin of victory, the actual difference in points scored during the game adjusted. The use of replacement officials is negatively correlated with the margin of victory for the favored team. Interestingly, the spreads do not show much of a change. Thus, it seems that the uncertainty of the substitutes lead to changes in the game that is not incorporated into the betting markets. Finally, the uncertainty does not necessarily lead to more volatile outcomes, as would be captured by GapSpread, but rather support for the underdog.

As before, the goodness of fit measurements reflect poor models. Un-measurable randomness mostly drives the difference between the actual and anticipated values.

Are there profitable betting opportunities? It is common for a bet on the spread to pay 110. This means that if $\$ 110$ is wagered and the bet wins, then $\$ 100$ is gained. Consequently, for a risk-neutral, wealth-maximizing individual the probability a bet wins must exceed 0.5238 (= 110/210) for it to be profitable. Would betting on the underdog have been profitable? During the first three weeks the favored team covered the spread $47.92 \%$ of time. Hence, the chance a bet on the underdog wins is 0.5208 , which is too low. Thus, the bet is not profitable. The econometric results presented in Table 3 also report that the accuracy of the spread depends on the size of the spread. Since the mean value of Spread reported in Table 1 is 5.09, the games during the first three weeks are subdivided into those with spreads greater than the mean from those less. The probability a bet for the not-favored team with a spread greater than five wins is 0.75 , which is 
well above the needed threshold of 0.5238 . Consequently, a bet for the underdog when replacement officials are working and the spread is greater than five returns $42.3 \%$. Similarly, the econometric results in Table 3 indicate that the premium on the moneyline bets is also correlated with accuracy of the spread. Again, the games with the replacement referees are subdivided into those with a premium above and below the mean value of 1.0333. The probability the not-favored team wins the bet is 0.56 for games with a greater-than-mean premium. Again, this is above the needed threshold. Consequently, such bets provide an expected $6.9 \%$ return.

As a final question, since it has been shown, studying the margin of victory, that the favored team in a game does relatively worse, it can be asked whether the replacement referees had an effect on the winner of the game. Rather are underdogs more likely to win? This question is addressed in two ways. Table 6 presents the results of a logit estimation with both Favored and Cover as the dependent variable. Favored is a dummy variable equal to one if the team favored to win the game actually wins. Cover is a dummy variable equal to one if the team favored to win the game wins by more points than anticipated, or rather, if they cover the spread. Each specification includes a constant term and all control variables previously used. Clustered standard errors are reported in parentheses and the marginal effects are provided in brackets.

[Insert Table 6 here.]

The results conform to the previous findings. The use of replacement referees lead to a statistically significant decrease in the likelihood of the favored team winning the game. The effect is robust to the specification and, while not reported, persists if a probit specification is 
alternatively estimated. The probability the favored team wins decreases by 15.1 to 16.0 percentage points. Similarly, the probability the favored team covers the spread decreases by 16.1 to 16.5 percentage points.

Also, while not reported, the use of replacement referees does not have a statistically significant effect on the probability that either the home team is favored to win the game or the chance the home team wins the game. Thus, the effect does not seem to be a bias for (or against) the home team, but rather support for the underdog.

As a final check on the robustness of the results the analysis was replicated using the 2011 NFL season and betting lines. ${ }^{9}$ A dummy variable First3, which is equal to one if the game occurred in the first three weeks of the season, is included in the specification. This analysis is done to identify whether or not betting irregularities tend to occur in the early weeks of a season. If inaccuracies occur in the first three weeks of the 2011 season, then it can be argued that the previous results may not be due to replacement referees but rather by the games occurring in the early part of the season.

The coefficient on First3 is close to zero and highly insignificant when the margin of victory dependent variables (OffSpread, Margin, Spread) are used. Similarly, it has no statistically significant effect when total scoring dependent variables (OffOU, Total, $O U$ ) are examined. Furthermore, there is no effect on the likelihood that the favored team either wins or covers the spread. As a result, one can be confident that the results previously derived identify a inaccuracy in betting markets with the replacement officials and that the result is not driven by being in the first three weeks.

\footnotetext{
${ }^{9} 2011$ NFL odds are obtained from thespread.com. Moneyline bets are not available and, thus, Premium cannot be included. Furthermore, since only one set of lines are available Spread5 and Money5 cannot be controlled for.
} 


\section{CONCLUSION}

Do betting markets accurately incorporate new information into the "prices" of the bets made? The quasi-experiment of the use of replacement referees in the NFL during the 2012 season provides the opportunity to address this question. By considering changes in on-the-field outcomes and betting market responses during the same season, heterogeneity over time can be mitigated.

Both the spread and the total bets exhibit distortions with the replacement referees. More points were scored, but there was not an adjustment in the over-under betting lines. The favored team also won by a smaller margin. The spreads did not anticipate this change. Consequently, a wedge was created and successful bets on the underdog team arose. Profitable betting opportunities arise. This suggests that betting markets do not necessarily incorporate all available information into their lines.

While it was speculated in the media that referees would be subject to pressure from home team fans and, thus, give an advantage to the home team, no effect was found. Alternatively, though, the favored team is both less likely to win and less likely to cover the spread with the replacement referees. These results cannot be replicated in the prior season and is therefore not an effect of time of year, but due to the referees.

The results point to the impact of uncertainty on betting markets. Oddmakers frequently refer to experience and past history when discussing how betting lines are determined. When new situations arise, uncertainty is created and the typical methods used to create expectations fail. Future work should consider whether this phenomenon occurs in other asset markets. 


\section{REFERENCES}

Borghesi, Richard (2007a), The Late-Season Bias: Explaining the NFL’s Home Underdog Effect, Applied Economics 39(15), 1889-1903.

Borghesi, Richard (2007b), The Home Team Weather Advantage and Biases in the NFL Betting Market, Journal of Economics and Business 59(4), 340-354.

Borghesi, Richard (2008), Weather Biases in the NFL Totals Market, Applied Financial Economics 18(2), 947-953.

Boulier, Bryan, H.O. Stekler, and Sarah Amundson (2006), Testing the Efficiency of the National Football League Betting Market, Applied Economics 38(3), 279-284.

Chin, Daniel M. (2011), A Test of Unbiasedness and Sports Book Profits in the NFL Point Spread Betting Market Using Circadian Advantage, Journal of Gambling Business and Economics 5(3), 1526.

Dare, William and Steven Holland (2004), Efficiency in the NFL Betting Market: Modifying and Consolidating Research Methods, Applied Economics 36, 9-15.

Dare, William and Scott MacDonald (1996), A Generalized Model for Testing the Home and Favorite Team Advantage in Point Spread Markets, Journal of Financial Economics 40(2), 295318. 
Golec, Joseph and Maurry Tomarkin (1991), The Degree of Inefficiency in the Football Betting Market, Journal of Financial Economics 30, 311-323.

Gray, Philip and Stephen Gray (1997), Testing Market Efficiency: Evidence from the NFL Sports Betting Market, Journal of Finance 52(4), 1725-1737.

Humphreys, Brad R. (2010), Price, Point Spreads and Profits: Evidence from the National Football League, Working Paper.

Lacey, Nelson (1990), An Estimation of Market Efficiency in the NFL Point Spread Betting Market, Applied Economics 22(1), 117-129.

Levitt, Steven (2004), Why are Gambling Markets Organized so Differently from Financial Markets?, Economic Journal 114, 223-246.

Nichols, Mark W. (2014), The Impact of Visiting Team Travel on Game Outcomes and Biases in NFL Betting Markets, Journal of Sports Economics 15(1), 78-96.

Ottaviani, Marco and Peter Norman Sørenson (2009), Surprised by Parimutuel Odds?, American Economic Review 99(5), 2129-2134.

Paul, Rodney J. and Andrew P. Weinbach (2002), Market Efficiency and a Profitable Betting Rule, Journal of Sports Economics 3(3), 256-263. 
Paul, Rodney J. and Andrew P. Weinbach (2007), Does Sportsbook.com Set Point Spreads to Maximize Profits? Tests of the Levitt Model of Sportsbook Behavior, Journal of Prediction Markets 1(3), 209-218.

Vergin, Roger (2001), Overreaction in the NFL Point Spread Market, Applied Financial Economics 11(5), 497-509.

Vergin, Roger and John Sosik (1999), No Place Like Home: An Examination of the Home Field Advantage in Gambling Strategies in NFL Football, Journal of Economics and Business 41(1), 21-31.

Woodland, Bill M. and Linda M. Woodland (1991), The Effects of Risk Aversion on Wagering: Point Spread Versus Odds, Journal of Political Economy 99(3), 638-653. 
TABLE 1: Variable Descriptions

\begin{tabular}{|c|c|c|c|c|}
\hline Label & Description & mean & $\min$ & $\max$ \\
\hline Spread & average spread & 5.09 & 0.1 & 16.8 \\
\hline Margin & pts for favored - pts for not favored & 5.88 & -34 & 58 \\
\hline OffSpread & Margin-Spread & 0.79 & -40 & 47.7 \\
\hline GapSpread & |Margin - Spread | & 11.00 & 0 & 47.7 \\
\hline OU & average over-under & 44.80 & 34 & 55.1 \\
\hline Total & total points actually scored & 45.52 & 13 & 85 \\
\hline OffOU & Total - OU & 0.72 & -31.3 & 39.4 \\
\hline GapOU & $\mid$ Total - OU & 10.38 & 0 & 39.4 \\
\hline Replace & $=1$ if during Week 1,2 , or 3 & & 0.187 & \\
\hline Thursday & $=1$ if game on Thursday night & & 0.070 & \\
\hline Monday & $=1$ if game on Monday night & & 0.062 & \\
\hline Home & $=1$ if home team is favored to win & & 0.560 & \\
\hline Roof & $=1$ if played in domed stadium & & 0.288 & \\
\hline Money5 & $=1$ if moneyline available from all fi & & 0.638 & \\
\hline Spread5 & = 1 if spread/ou available from all fiv & & 0.984 & \\
\hline$A F C$ & $=1$ if home team is in the AFC & & 0.471 & \\
\hline Conference & $=1$ if teams are conference opponent & & 0.716 & \\
\hline
\end{tabular}


TABLE 2: Referee Subsamples

\begin{tabular}{lll}
\hline & $\begin{array}{l}\text { Replacement } \\
\text { Referees }\end{array}$ & $\begin{array}{l}\text { Regular } \\
\text { Referees }\end{array}$ \\
\hline $\begin{array}{lll}\text { Offpread } \\
\text { OffOU }\end{array}$ & -2.46 & 1.54 \\
$\begin{array}{l}\text { \% of games where } \\
\text { the favored team wins }\end{array}$ & 2.68 & 0.27 \\
\hline
\end{tabular}


TABLE 3: Accuracy of the Spread

(dependent variable $=$ OffSpread $)$

\begin{tabular}{|c|c|c|c|}
\hline & I & II & III \\
\hline Replace & $\begin{array}{l}-4.142 * * * \\
(1.534)\end{array}$ & $\begin{array}{l}-3.829 * * * \\
(1.351)\end{array}$ & $\begin{array}{l}-3.675 * * * \\
(1.250)\end{array}$ \\
\hline Thursday & $\begin{array}{l}1.814 \\
(2.894)\end{array}$ & $\begin{array}{l}1.794 \\
(3.027)\end{array}$ & $\begin{array}{l}1.677 \\
(3.115)\end{array}$ \\
\hline Monday & $\begin{array}{l}2.022 \\
(3.180)\end{array}$ & $\begin{array}{l}1.401 \\
(3.421)\end{array}$ & $\begin{array}{l}1.673 \\
(3.515)\end{array}$ \\
\hline Home & $\begin{array}{l}-1.963 \\
(1.976)\end{array}$ & $\begin{array}{l}-1.984 \\
(1.994)\end{array}$ & $\begin{array}{l}-2.575 \\
(1.984)\end{array}$ \\
\hline Roof & $\begin{array}{l}-5.962 * * * \\
(2.251)\end{array}$ & $\begin{array}{l}-5.880 * * * \\
(2.203)\end{array}$ & $\begin{array}{l}-5.988 * * * \\
(2.189)\end{array}$ \\
\hline Money5 & $\begin{array}{l}2.600 * * \\
(1.232)\end{array}$ & $\begin{array}{l}3.873 * * * \\
(1.308)\end{array}$ & $\begin{array}{l}3.650 * * * \\
(1.328)\end{array}$ \\
\hline Spread5 & $\begin{array}{l}-2.173 \\
(6.560)\end{array}$ & $\begin{array}{l}-1.651 \\
(6.578)\end{array}$ & $\begin{array}{l}-1.352 \\
(6.529)\end{array}$ \\
\hline$A F C$ & $\begin{array}{l}-1.122 \\
(2.009)\end{array}$ & $\begin{array}{l}-1.186 \\
(2.031)\end{array}$ & $\begin{array}{l}-1.595 \\
(1.980)\end{array}$ \\
\hline Conference & $\begin{array}{l}0.870 \\
(2.161)\end{array}$ & $\begin{array}{l}0.653 \\
(2.084)\end{array}$ & $\begin{array}{l}0.612 \\
(2.124)\end{array}$ \\
\hline Premium & & $\begin{array}{l}495.033 * * \\
(213.102)\end{array}$ & $\begin{array}{l}529.526 * * \\
(210.513)\end{array}$ \\
\hline Spread & & & $\begin{array}{l}0.487 * * * \\
(0.168)\end{array}$ \\
\hline $\operatorname{adj} R^{2}$ & 0.024 & 0.038 & 0.047 \\
\hline AIC & 2096.6 & 2093.8 & 2092.5 \\
\hline $\mathrm{F}$ & $2.33 * *$ & $4.61 * * *$ & $5.665 * *$ \\
\hline
\end{tabular}


TABLE 4: Accuracy of the Over-Under (dependent variable $=$ OffOU)

\begin{tabular}{|c|c|c|c|}
\hline & I & II & III \\
\hline Replace & $\begin{array}{l}2.630 * \\
(1.501)\end{array}$ & $\begin{array}{l}2.681 * \\
(1.471)\end{array}$ & $\begin{array}{l}2.696 * \\
(1.470)\end{array}$ \\
\hline Thursday & $\begin{array}{l}-3.673 \\
(4.632)\end{array}$ & $\begin{array}{l}-3.678 \\
(4.695)\end{array}$ & $\begin{array}{l}-3.610 \\
(4.783)\end{array}$ \\
\hline Monday & $\begin{array}{l}-5.513 * \\
(3.250)\end{array}$ & $\begin{array}{l}-5.613 * \\
(3.329)\end{array}$ & $\begin{array}{l}-5.620 * \\
(3.306)\end{array}$ \\
\hline Home & $\begin{array}{l}0.901 \\
(1.857)\end{array}$ & $\begin{array}{l}0.898 \\
(1.856)\end{array}$ & $\begin{array}{l}0.0849 \\
(1.802)\end{array}$ \\
\hline Roof & $\begin{array}{l}1.685 \\
(1.598)\end{array}$ & $\begin{array}{l}1.699 \\
(1.599)\end{array}$ & $\begin{array}{l}1.728 \\
(1.606)\end{array}$ \\
\hline Money5 & $\begin{array}{l}-0.519 \\
(1.964)\end{array}$ & $\begin{array}{l}-0.314 \\
(2.054)\end{array}$ & $\begin{array}{l}-0.263 \\
(2.067)\end{array}$ \\
\hline Spread5 & $\begin{array}{l}7.533 * * \\
(3.317)\end{array}$ & $\begin{array}{l}7.617 * * \\
(3.386)\end{array}$ & $\begin{array}{l}7.561 * * \\
(3.423)\end{array}$ \\
\hline$A F C$ & $\begin{array}{l}0.011 \\
(1.643)\end{array}$ & $\begin{array}{l}0.000 \\
(1.657)\end{array}$ & $\begin{array}{l}-0.024 \\
(1.693)\end{array}$ \\
\hline Conference & $\begin{array}{l}-2.831 \\
(2.576)\end{array}$ & $\begin{array}{l}-2.867 \\
(2.581)\end{array}$ & $\begin{array}{l}-2.847 \\
(2.559)\end{array}$ \\
\hline Premium & & $\begin{array}{l}79.908 \\
(173.103)\end{array}$ & $\begin{array}{l}83.617 \\
(171.221)\end{array}$ \\
\hline$O U$ & & & $\begin{array}{l}-0.056 \\
(0.164)\end{array}$ \\
\hline $\operatorname{adj} R^{2}$ & 0.005 & 0.001 & -0.002 \\
\hline AIC & 2067.4 & 2069.2 & 2071.1 \\
\hline $\mathrm{F}$ & $4.34 * * *$ & $5.53 * * *$ & $7.80 * * *$ \\
\hline \multicolumn{4}{|c|}{$\begin{array}{l}* * * 1 \%, * * 5 \%, * 10 \% \text { level of significance } \\
\text { Standard errors clustered by week reported in the parentheses. } \\
\text { A constant term is included but not reported. }\end{array}$} \\
\hline
\end{tabular}


TABLE 5: Additional Results

\begin{tabular}{|c|c|c|c|c|c|c|}
\hline & $\begin{array}{l}\text { Replace } \\
\text { coefficient }\end{array}$ & \multicolumn{2}{|c|}{ standard error } & \multicolumn{2}{|c|}{ Goodness of Fit } & $\mathrm{F}$ \\
\hline GapSpread & -0.125 & $(0.974)$ & -0.022 & 1873.2 & $2.20 * *$ & \\
\hline GapOU & 1.368 & $(0.906)$ & 0.001 & 2069.2 & $5.99 * *$ & \\
\hline Spread & -0.271 & $(0.405)$ & 0.027 & 1345.0 & $3.00 * * *$ & \\
\hline Margin & $-4.413 * *$ & $(1.802)$ & 0.019 & 2121.2 & $3.61 * * *$ & \\
\hline$O U$ & 0.232 & $(0.440)$ & -0.008 & 1508.7 & 1.12 & \\
\hline Total & $2.863 * *$ & (1.180) & -0.001 & 2092.3 & $4.99 * * *$ & \\
\hline
\end{tabular}


TABLE 6: Likelihood the Favored Team Wins

(dependent variable $=$ Favored $\&$ Cover $)$

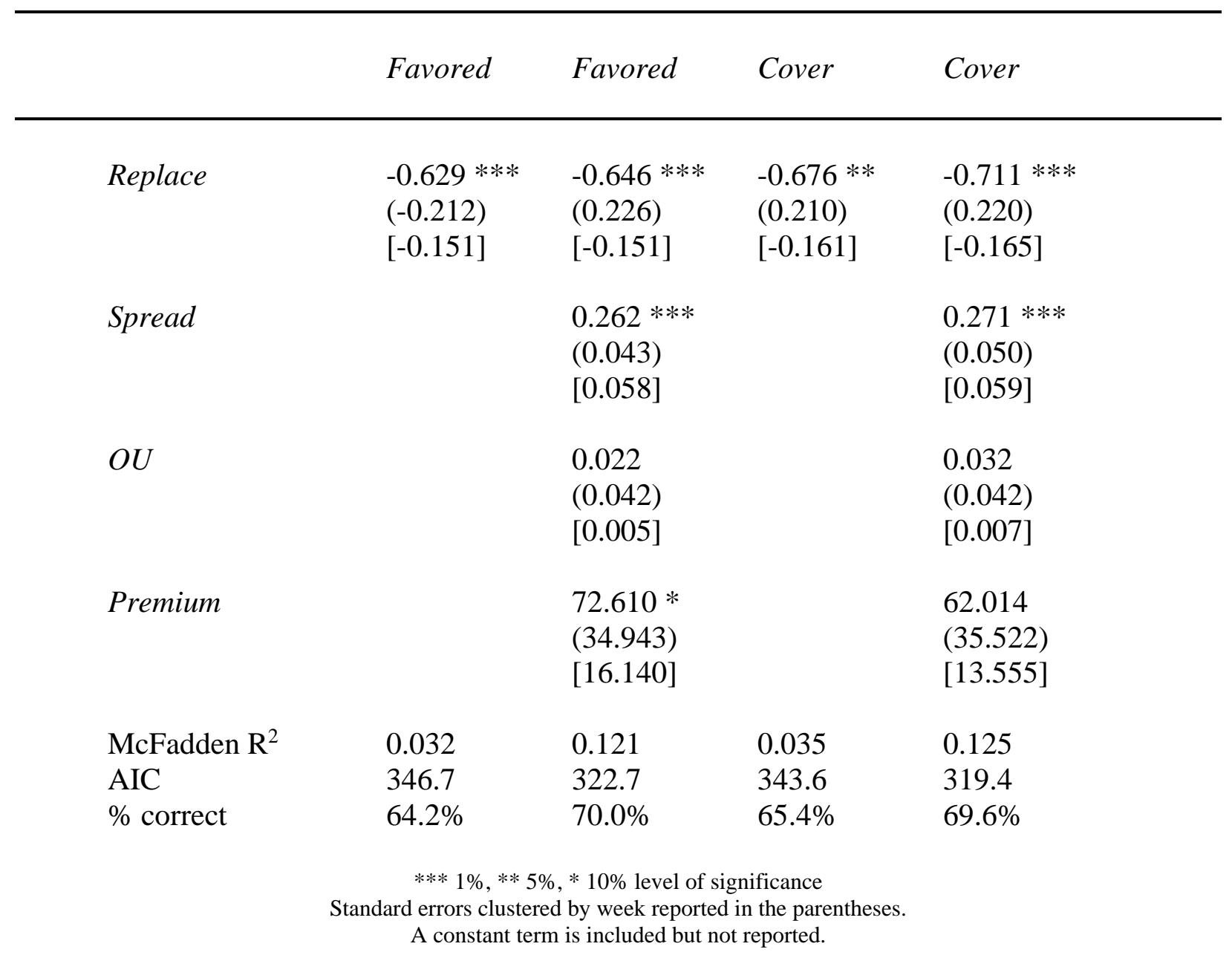

